\title{
Experimental study on heat transfer characteristics of horizontal concentric tube using twisted wire brush inserts
}

\author{
Shravani A. Phule ${ }^{+*}$ and Kundlik V. Mali ${ }^{\ddagger}$ \\ †Department of Mechanical Engineering, Sinhgad College of Engineering, Pune, India \\ ^Department of Mechanical Engineering, MAEER's MIT College of Engineering, Pune, India \\ Accepted 02 March 2016, Available online 15 March 2016, Special Issue-4 (March 2016)
}

\begin{abstract}
In the present study, heat transfer from hot water to cold water by double pipe heat exchanger for plain tube and plain tube with twisted wire brush inserts is experimentally investigated. The experiments were carried out for counter flow configuration with hot water in the inner tube and cold water flowing in the annulus through outer tube. All the experiments were conducted by varying hot water Reynolds number at constant cold water Reynolds number in the laminar flow region. The horizontal double pipe heat exchanger is made from straight copper tube with inner tube and outer tube diameters of 15 and $25 \mathrm{~mm}$, respectively. The twisted wire brush inserts were fabricated by winding a $0.2 \mathrm{~mm}$ diameter of the copper wires over a $2 \mathrm{~mm}$ diameter two twisted iron core-rods. All the required parameters like inlet and outlet temperature of hot and cold water, flow rates of both hot and cold water were measured using appropriate instruments. Effect of inlet fluid temperature and other relevant parameters on heat transfer characteristics and pressure drop were studied. The convective heat transfer coefficient of double pipe heat exchanger under various operating conditions was determined.
\end{abstract}

Keywords: Twisted wire brush inserts, double pipe heat exchanger, Heat transfer enhancement

\section{Introduction}

Heat exchangers have several industrial and engineering applications. Heat exchangers also find its application in various processes like conversion, utilization and recovery of thermal energy in industrial, commercial and domestic applications. The design of heat exchangers is quite complicated as it requires exact analysis of heat transfer rate and pressure drop apart from its efficient performance and economy of the system. The major challenge while designing is to achieve high heat transfer with decreased pressure drop and minimum pumping power along with a compact design of a heat exchanger. Use of heat transfer enhancement techniques lead to increase in heat transfer coefficient but at the cost of increase in pressure drop. Wide range of inserts such as tapered spiral insert, packing, rings, discs, streamlined shapes, mesh inserts, spiral brush inserts, conical-nozzles and V-nozzles have been widely used to minimize the size of heat exchanger and thereby reduce the capital cost for a given load.

Paisarn Naphon et al. (2011) investigated the heat transfer characteristics and the pressure drop of the horizontal concentric tube with twisted wires brush inserts. The plain tube with full-length twisted wires

*Corresponding author: Shravani A. Phule brush and regularly spaced twisted wires brush with $30 \mathrm{~cm}$ spacer length inserts were tested. Cold and hot water were used as working fluids for counter flow configuration, respectively. The effect of twisted wires density, inlet fluid temperature, and relevant parameters on heat transfer characteristics and pressure drop were studied.

It was found that the twisted wire brush inserts have a large effect on the enhancement of heat transfer, however, the pressure drops also increase. P. Promvonge et al. (2007) experimentally investigated the heat transfer, friction factor and enhancement efficiency characteristics in a circular tube fitted with conical-ring turbulators and a twisted-tape swirl generator. The heat transfer test section is heated electrically.

In the experiments, two enhancement heat transfer devices were used. One is the conical-ring used as a turbulator and placed in the tested tube and the other is the twisted-tape swirl generator placed at the core of the conical-ring. Air was used as a working fluid. It was found that there is significant increase in heat transfer value and the enhancement efficiency tends to decrease with the rise in Reynolds number. Also, correlations were developed to predict Nusselt number, friction factor for circular tube using the conical ring turbulator and swirl generator. K. V 
Sharma et al. (2009) conducted experiments to evaluate heat transfer coefficient and friction factor for flow in a tube and with twisted tape inserts in the transition range of flow with $\mathrm{Al}_{2} \mathrm{O}_{3}$ nanofluid. It was found that there is considerable enhancement of convective heat transfer with $\mathrm{Al}_{2} \mathrm{O}_{3}$ nanofluids as compared to water. The heat transfer coefficient of nanofluid flowing in a tube with $0.1 \%$ volume concentration is $23.7 \%$ higher when compared with water at number of 9000 . Heat transfer coefficient and pressure drop with nanofluid has been determined with tapes of different twist ratios. A regression equation was developed to estimate the Nusselt number which was valid for both water and nanofluid flowing in circular plain tube and with tape inserts. M.M.K. Bhuiya et al. carried out experimental study on the heat transfer performance and friction factor characteristics in a circular tube using twisted wire brush inserts. The study was conducted for flow in turbulent region. The results indicated that the presence of twisted wire brush inserts led to a large effect on the enhancement of heat transfer with corresponding increase in friction factor for the plain tube. It was also found that there was considerable increase in Nusselt number value with increasing Reynolds number. Further correlations were also developed to predict heat transfer, friction factor, and thermal performance factor for turbulent flow through a circular tube fitted with the twisted wire brush inserts in terms of wire density (y), Reynolds number (Re), and Prandtl number (Pr). M. A. AkhavanBehabadi et al. (2010) carried out investigation to study the enhancement in heat transfer coefficient by coiled wire inserts during heating of engine oil inside a horizontal tube. The test-section was a double pipe counter-flow heat exchanger. The engine oil flowed inside the internal copper tube, while saturated steam, used for heating the oil, flowed in the annulus. The data was obtained for heated engine oil flowing through the plain tube. The effects of Reynolds number and coiled wire geometry on the heat transfer enhancment and fanning friction factor were studied. Empirical correlations were developed to predict the heat transfer enhancement of these coiled wire inserts. According to the results obtained, it was seen that wire coil inserts with lower wire diameters give better performance at low Reynolds numbers.

\section{Experimental apparatus and method}

The important parts of experimental set-up are the test section, hot and cold water tanks, rotameters, monoblock pumps, whose selection is already discussed in previous section. All these instruments are selected as per the requirements depending upon their measuring range, accuracy and availability in the market. The test section is made up of copper tubes as it has higher thermal conductivity. The proposed experimental set-up is shown in Fig. 1 which is fabricated for water to water single phase heat exchanger system.

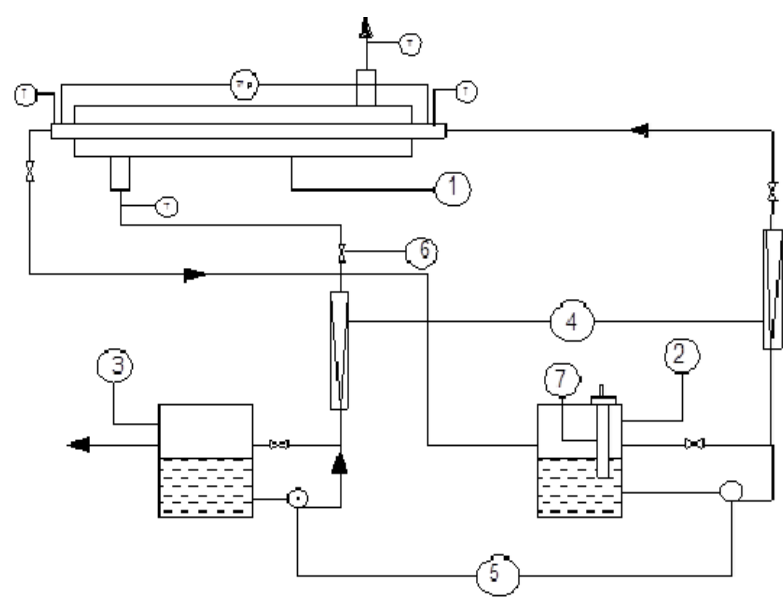

1. Double pipe heat exchanger (Test section)

2. Hot water storage tank

3. Cold water storage tank

4. Rotameters

5. Monoblock pumps

6. Flow control Valve

7. Water heater

Fig.1 Schematic diagram of proposed experimental setup

\subsection{Technical details of twisted wire brush inserts}

The geometrical configuration and details of the twisted wires brush inserts are shown in Fig. 2. The test section is the horizontal double pipe heat exchanger. It is made from straight copper tube with inner tube and outer tube diameters of $15 \mathrm{~mm}$ and 25 $\mathrm{mm}$, respectively. The plain tubes with full-length twisted wires and with regularly spaced twisted wires brush inserts are tested. The twisted wires brush inserts are fabricated by winding a $0.2 \mathrm{~mm}$ diameter of the copper wires over a $2 \mathrm{~mm}$ diameter two twisted iron core-rods.

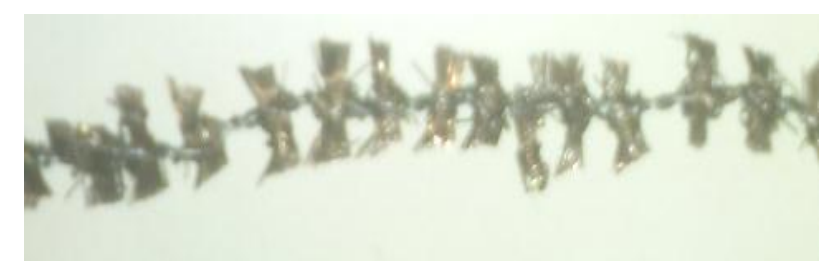

Fig.2 Geometric details of twisted wire brush inserts

\subsection{Experimental Apparatus}

The schematic diagram of the experimental apparatus is shown in Fig.3. It consists of a test section, hot water loop, cold water loop and data acquisition system. The experimental set-up is a concentric double pipe heat exchanger which is well equipped with required instruments and gives heat transfer between hot water flowing through inner pipe and cold water flowing through outer pipe. The heat exchanger includes two concentric copper tubes with twisted wire brush inserts in inner tube. The test section and the piping 
system were designed in such a way that all parts can have easy access and repaired easily. A full set of instruments was used to measure and control temperature and flow rates of water and are located at desired points in the set-up. The hot water was adjusted to desired level and is controlled with the help of dimmerstat. Two way flow control valves were used to maintain the flow rate of water both in inner as well as outer tube. These valves were selected for half inches piping. Galvanised pipes were used for the tubing connection in set-up. The inlet and outlet temperatures of water in inner and outer tube were measured with PT-100 type of thermocouples located at desired points for temperature measurement. The accuracy of thermocouple is $\pm 0.1^{\circ} \mathrm{C}$. To determine the pressure drop across the test section, manometer having range 100-0-100 $\mathrm{mm}$ was used. Depending upon the variation of Reynolds number from 500 to 3000 suitable Rotameter having a range of 15 to 150 $\mathrm{LPH}$ is selected.

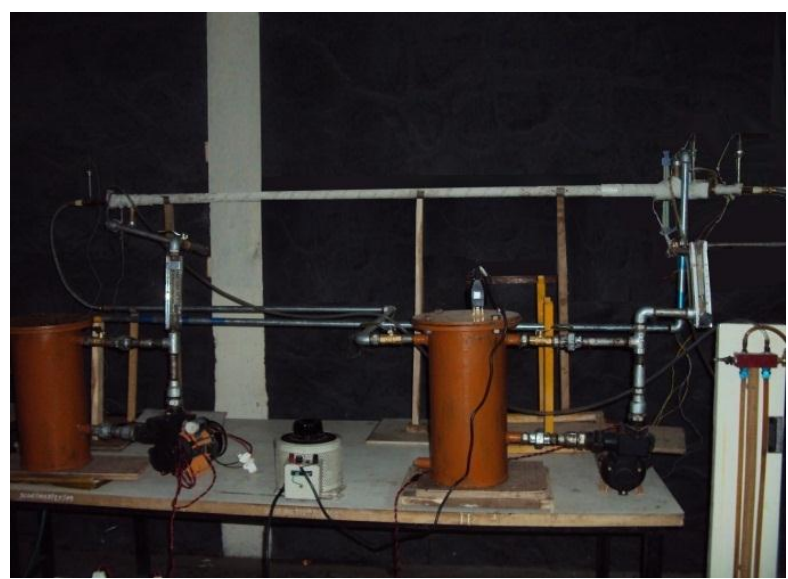

Fig.3 Experimental Set-up diagram

The characteristic dimensions of double pipe heat exchanger with twisted wire brush inserts are presented in Table.1

Table 1 Characteristic dimensions of double pipe heat exchanger and wire brush inserts

\begin{tabular}{|c|c|}
\hline Parameters & Dimensions \\
\hline Diameter of the inner plain tube $\left(\mathrm{D}_{\mathrm{i}}\right), \mathrm{mm}$ & 15 \\
\hline Diameter of the outer plain tube $\left(\mathrm{D}_{\mathrm{o}}\right), \mathrm{mm}$ & 25 \\
\hline Length of plain tube, $\mathrm{m}$ & 2 \\
\hline Number of twisted core rod & 2 \\
\hline Twisted wire brush length, $\mathrm{m}$ & 2 \\
\hline Twisted wire diameter, $\mathrm{mm}$ & 0.2 \\
\hline
\end{tabular}

\subsection{Experimental procedure}

The experimental set-up was installed for water-towater single phase heat exchanger system. It consists of double pipe heat exchanger, hot water tank, cold water tank, pumping device, U-tube manometer, and data acquisition system. The experiments were performed for various flow rates and constant inlet temperature of hot water entering test section. The water flow rate was increased in small increments by keeping the cold water flow rate, inlet cold water temperature and hot water temperature constant. The inlet hot water temperature was adjusted to desired level by using electric heater and the corresponding temperature was controlled by using dimmerstat Before noting down the observations, the system was allowed to approach steady state. The experiments were carried out for the concentric plain tube and the concentric plain tube with full length twisted wire brush inserts. The flow rates of water were controlled by operating the flow control valve and by two rotameters. The water temperatures at inlet and outlet sections as well as average tube wall temperatures were measured by PT-100 type thermocouples. A caliberated U-tube manometer was employed to measure pressure drop across the test section.

For the experimentation the cold water flow rates were varied from $30 \mathrm{LPH}$ to $70 \mathrm{LPH}$ while hot water flow rates were varied from $15 \mathrm{LPH}$ to $75 \mathrm{LPH}$. The inlet cold and hot water temperatures are taken in operating range of $24-26^{\circ} \mathrm{C}$ and $40-45^{\circ} \mathrm{C}$, respectively.

\section{Data reduction}

The data was collected for plain tube as well tube with twisted wire brush inserts. The different flow rates for cold water and hot water are taken for counter flow heat exchanger.

The heat transfer rate for cold water in the test section, $\mathrm{Q}_{\mathrm{c}[1\}}$, can be expressed as,

$\mathrm{Q}_{\mathrm{c}}=\mathrm{m}_{\mathrm{c}} \mathrm{C}_{\mathrm{pc}}\left(\mathrm{T}_{\mathrm{co}}-\mathrm{T}_{\mathrm{ci}}\right)$

Where, $m_{c}$ is the flow rate of cold water, $C_{p c}$ is the specific heat of water; $\mathrm{T}_{c o}$ and $\mathrm{T}_{\mathrm{ci}}$ are outlet and inlet cold water temperatures respectively.

The heat transfer rate for hot water in the test section, $\mathrm{Q}_{\mathrm{h}[1]}$, can be expressed as,

$\mathrm{Q}_{\mathrm{h}}=\mathrm{m}_{\mathrm{h}} \mathrm{C}_{\mathrm{ph}}\left(\mathrm{T}_{\mathrm{hi}}-\mathrm{T}_{\mathrm{ho}}\right)$

Where, $m_{h}$ is the flow rate of hot water, $C_{p h}$ is the specific heat of water, $\mathrm{T}_{\text {ho }}$ and $\mathrm{T}_{\mathrm{hi}}$ are outlet and inlet hot water temperatures respectively.

All the fluid thermophysical properties are calculated at the average of inlet and outlet hot fluid temperatures.

The average heat transfer rate obtained by is calculated for hot and cold water which is used to calculate the inner convective heat transfer coefficient. The thermal equilibrium test showed that the heat transfer rate on cold side is less than heat transfer rate obtained for hot water. This indicates that there are some heat losses on the outer surface of test section. 
The average heat transfer rate, $\mathrm{Q}_{\mathrm{ave}}$ [1] is determined as follows,

$\mathrm{Q}_{\mathrm{ave}}=\left(\mathrm{Q}_{\mathrm{c}}+\mathrm{Q}_{\mathrm{h}}\right) / 2$

This average heat transfer rate can be used to calculate inner convective heat transfer coefficient.

The heat transfer coefficient can be calculated using various methods such as using Wilson plot technique. But, in the present study, the tube side heat transfer coefficient for the inner tube can be evaluated from the average heat transfer rate obtained from the equation as follows,

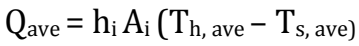

where, $\mathrm{T}_{\mathrm{s}, \mathrm{ave}}$ is the average tube wall temperature, $\mathrm{T}_{\mathrm{h} \text {,ave }}$ is the average hot water temperature, $\mathrm{A}_{\mathrm{i}}$ is the inside surface area of the inner tube and $h_{i}$ is the convective heat transfer coefficient of inner tube.

The experimental Nusselt number can be calculated from the equation given as below,

$\mathrm{Nu}=\mathrm{h}_{\mathrm{i}} \mathrm{D}_{\mathrm{i}} / \mathrm{k}$

A number of correlations are developed for laminar flow region, but the one most widely recommended is the Hausen correlation[1] which is taken for reference and is given as,

$N u=\left\{3.65+\frac{0.0668 \operatorname{Re} \operatorname{Pr}\left(\frac{d i}{L}\right)}{1+0.04\left[\operatorname{Re} \operatorname{Pr}\left(\frac{d i}{L}\right)\right]^{0.66}}\right\} \frac{\mu_{i}^{0.14}}{\mu_{w}}$

where, $\mathrm{Re}$ is hot water Reynolds number, $\mathrm{Pr}$ is hot water Prandtl number, $d_{i}$ is inner tube diameter, length of inner tube, $\mu_{\mathrm{i}}$ is the fluid viscosity in inner pipe and $\mu_{w}$ is the wall viscosity of inner pipe.

The friction factor correlations can be referred from available literature review, which are as follows,

$\mathrm{f}=0.448 \mathrm{Re}^{-0.275}$

The above correlation is known as Blausius equation which is the proposed relation to determine friction factor.

The experimental correlation for the friction factor is given as,

$f=\frac{\Delta P d_{h}}{2 \rho l v^{2}}$

Where, $\mathrm{l}$ is the length of heat exchanger, $d_{h}$ is the hydraulic diameter, $\Delta \mathrm{P}$ is pressure drop across heat exchanger, $\rho$ is the density of fluid, $v$ is the velocity of fluid.

\section{Results and discussion}

This section includes experimental study for concentric plain tube and tube with twisted wire brush inserts. The double pipe heat exchanger is analyzed in terms of temperature variation, heat transfer rate, friction factor and pressure drop. Various tests were performed for water to water heat transfer in double pipe having counter flow configuration with hot water flowing in inner tube and cold water flowing through outer tube. The results obtained from the experimental study of heat exchanger which was carried out at various operating conditions is discussed and presented in detail in the next section. A successful attempt is made to achieve maximum possible heat transfer from hot water to cold water using twisted wire brush inserts inside the pipe.

4.1 Comparison of Nusselt number obtained from plain tube and with full length twisted wire brush inserts

Fig. 4 represents the comparison between experimental results of plain tube and tube with twisted wire brush inserts. It also shows the relation between inside Nusselt number and inside Reynolds number. It can be observed that there is an increase in Nusselt number value with corresponding increase in Reynolds number. The inside Nusselt number for tube with twisted tube inserts is higher as compared to plain tube inside Nusselt number value. There is approximately $10 \%$ increase in Nusselt number for tube with twisted wire brush inserts as compared to plain tube value.

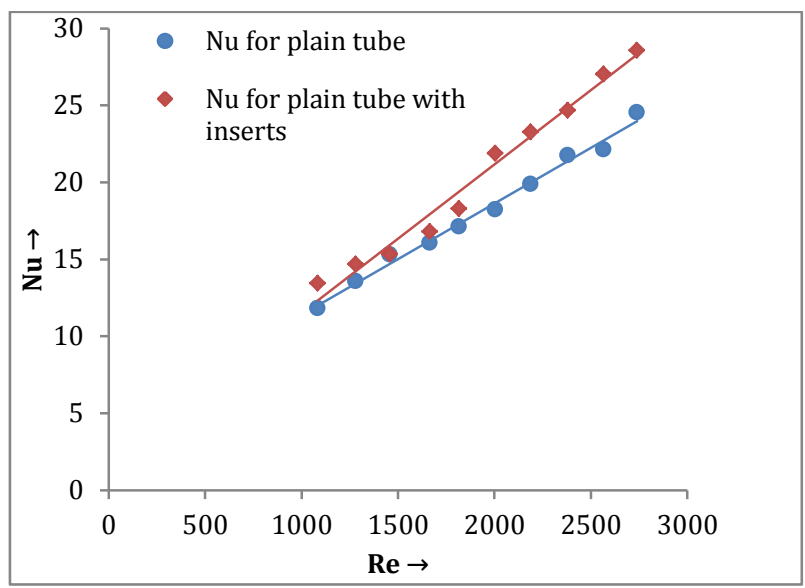

Fig.4 Variation of Nusselt number with Reynolds number for plain tube and plain tube with twisted wire brush inserts

Fig. 5 shows the variation of inner Nusselt Number with various mass flow rates for plain tube and tube with twisted wire brush inserts. It can be seen that inner tube side Nusselt number increases with increase in mass flow rate of hot water which flows through inner tube. The values of Nusselt number for tube with inserts are higher than values for plain tube. The 
performance of tube with twisted wire brush inserts is better than plain tube heat exchanger. The mass flow rate on hot water tube side is varied while mass flow rate on cold water side is kept constant.

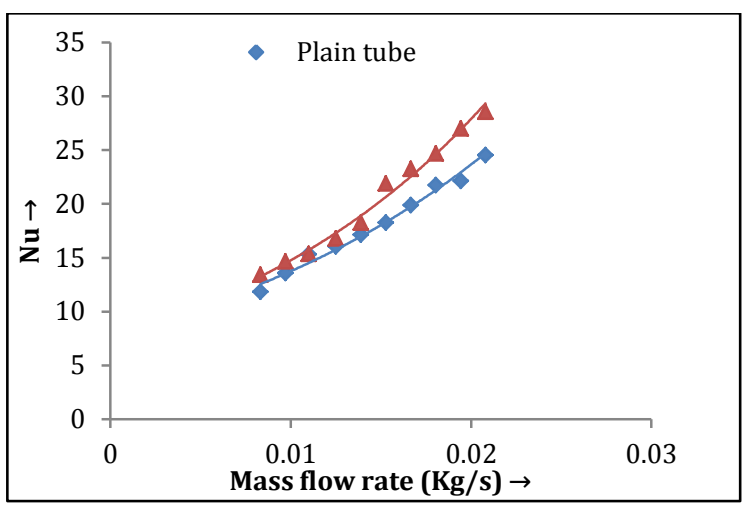

Fig.5 Variation of inner Nusselt Number with various mass flow rates for plain tube and tube with twisted wire brush inserts

\subsection{Effect on Average heat transfer rate for plain tube and tube with twisted wire brush inserts}

Fig. 6 shows the variation of average heat transfer rate with hot water Reynolds number for plain tube with full length twisted wire brush inserts.It is observed that at specific temperature of hot and cold water entering the heat exchanger, the heat transfer rate increases with increasing hot water Reynolds number. The reason for this is the heat transfer rate across the test section depends upon the heating capacity of hot water. It is observed from the Fig. 6 that the heat transfer from plain tube with full length twisted wire brush inserts is higher than those from the plain tube without twisted wire brush inserts. It is also found that when inlet hot and cold water temperatures, and cold water mass flow rate are kept constant, the average heat transfer rate increases with increasing hot water Reynolds number. This means that Nusselt number also increases. Comparing with Fig.4, it is observed that the variation of Nusselt number with hot water Reynolds number are similar to the trends of heat transfer rate and same explanation can be given.

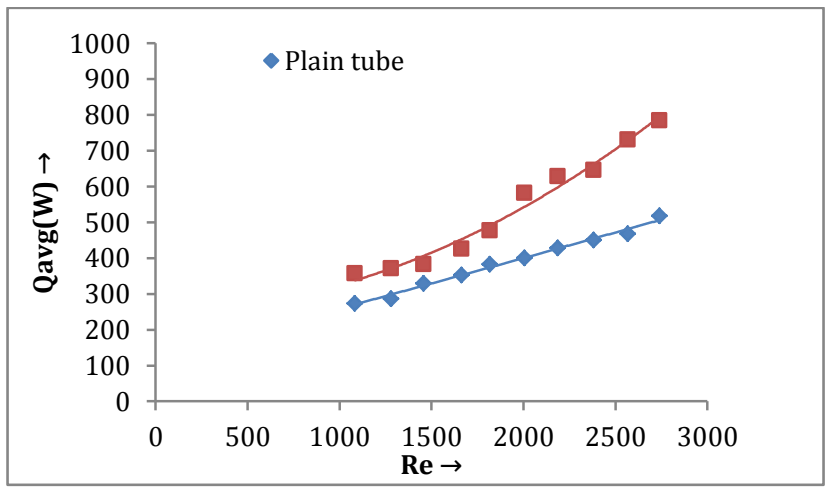

Fig.6 Variation of average heat transfer rate with Reynolds number for plain tube and tube with twisted wire brush inserts

\subsection{Effect on inner convective heat transfer coefficient} for plain tube and tube with twisted wire brush inserts

Fig. 7 shows the relation between inner convective heat transfer coefficient with Reynolds number for plain tube and tube with twisted wire brush inserts. The inner convective heat transfer coefficient on tube side increases with increasing hot water Reynolds number. Approximately there is $10-12 \%$ increase in inner convective heat transfer coefficient value for tube with full-length twisted wire brush inserts in comparison to plain tube values. This indicates the corresponding increase in value of Nusselt number values for tube without and with twisted wire brush inserts.

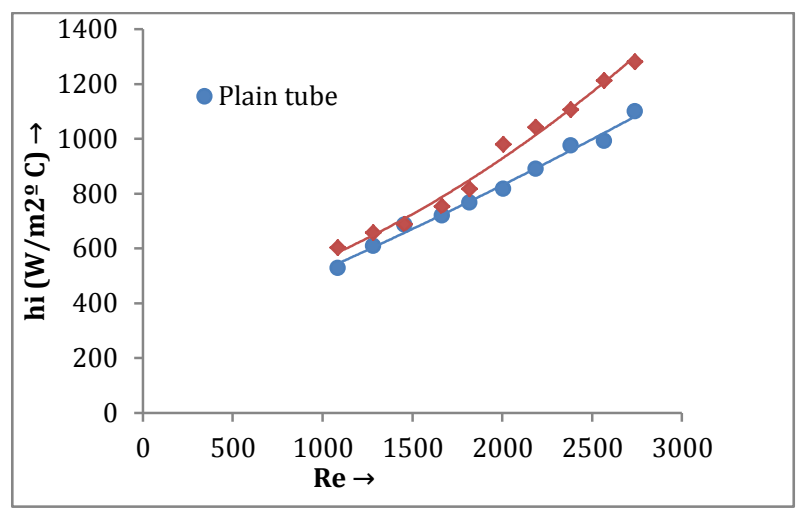

Fig.7 Variation of inner convective heat transfer coefficient with Reynolds number for plain tube and tube with twisted wire brush inserts

\subsection{Comparison of friction factor for plain tube and tube with twisted wire brush inserts}

Fig. 8 also shows the comparison of the friction factor between plain tube without twisted wire brush inserts and plain tube with full length twisted wire brush inserts.

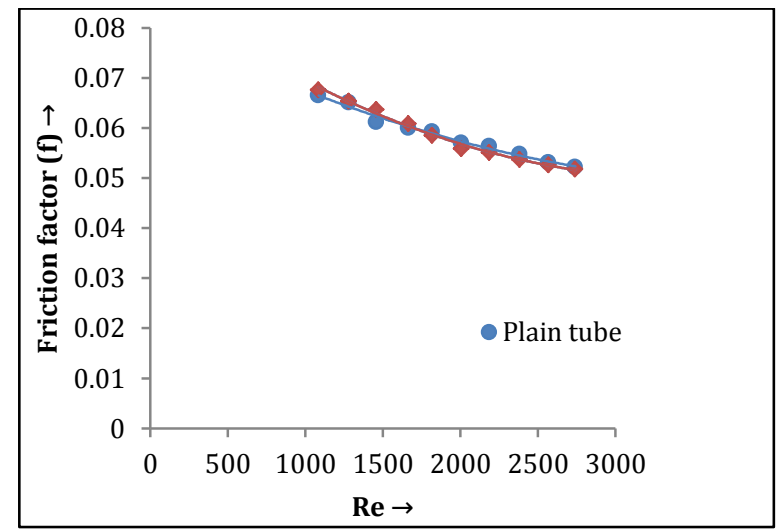

Fig.8 Variation of friction factor with Reynolds number for plain tube and with twisted wire brush inserts

It was clearly observed that the friction factor continues to decrease with hot water Reynolds number. The flow characteristics through the plain 
tube with twisted wire brush inserts is quite complicated than plain tube. This friction factor of the plain tube with twisted wire brush inserts is produced due to swirl generated because of inserts, drag forces exerted on the flow field by the twisted wire inserts and turbulence augmentation. As expected the friction factor obtained from plain tube with full length twisted wire brush inserts is higher than plain tube. But tha values of friction factor in both the cases are almost close.

\section{Conclusions}

An experimental study is conducted to investigate the heat transfer performance and friction factor characteristics for laminar flow through a tube by means of twisted wire brush inserts. The mass flow rates in inner tube and in annulus are varied during experimentation. Single phase water- water heat transfer study is performed and tested for counter flow configuration. Effect of inlet fluid temperature and relevant parameters on heat transfer characteristics and friction factor are considered. The study revealed that the twisted wire brush inserts provided significant enhancement of heat transfer with the corresponding increase in friction factor, however the pressure drop also increases too.
Due to the turbulence created and swirl flow generated, the convective heat transfer obtained from the tube with twisted wire brush inserts is higher than that with the plain tube without twisted wire brush inserts.

\section{References}

Paisarn Naphon, Tanapon Suchana, (2011), Heat transfer enhancement and pressure drop through the horizontal concentric tube with twisted wire brush inserts, International Communications in Heat and Mass transfer, 38, pp. 236-241.

P. Promvonge, S. Eiamsa-ard, (2007), Heat transfer behaviors in a tube with combined conical-ring and twisted-tape insert, International Communications in Heat and Mass Transfer, 34, pp.849-859.

Sarma. K. V., Sundar. L. S., Sarma. P. K, (2009), Estimation of heat transfer coefficient and friction factor in the transition flow with volume concentration of Al203 nanofluid flowing in a circular tube and twisted tape insert, International Communications in Heat and Mass transfer, 36, pp. 503-507.

M.M.K. Bhuiya, M.S.U. Chowdhury, Heat transfer performance evaluation for turbulent flow through a tube with twisted wire brush inserts, International Communications in Heat and Mass Transfer, 39, pp. 1505-1512.

M.A. Akhavan-Behabadi, Ravi Kumar, M.R. Salimpour, R. Azimi, (2010), Pressure drop and heat transfer augmentation due to coiled wire inserts during laminar flow of oil inside a horizontal tube, International Journal of Thermal Sciences, 49, pp.373-379. 